\title{
max \\ On the Use of Augmented Reality to Reinforce the Learning of Power Electronics for Beginners
}

\author{
Sergio Sandoval Pérez ${ }^{1}\left(\mathbb{D}\right.$, Juan Miguel Gonzalez Lopez ${ }^{2, *}\left(\mathbb{C}\right.$, Miguel Angel Villa Barba ${ }^{1}(\mathbb{D}$, \\ Ramon O. Jimenez Betancourt ${ }^{2}$, Jesús Ezequiel Molinar Solís ${ }^{1}{ }^{1}$, Juan Luis Rosas Ornelas ${ }^{3}$, \\ Gustavo Israel Riberth García ${ }^{3}$ and Fernando Rodriguez Haro ${ }^{2}$
}

\section{check for}

updates

Citation: Sandoval Pérez, S.

Gonzalez Lopez, J.M.; Villa Barba,

M.A.; Jimenez Betancourt, R.O.;

Molinar Solís, J.E.; Rosas Ornelas, J.L.; Riberth García, G.I.; Rodriguez Haro,

F. On the Use of Augmented Reality

to Reinforce the Learning of Power

Electronics for Beginners. Electronics 2022, 11, 302. https://doi.org/

$10.3390 /$ electronics 11030302

Academic Editor: Jeha Ryu

Received: 5 December 2021

Accepted: 14 January 2022

Published: 19 January 2022

Publisher's Note: MDPI stays neutral with regard to jurisdictional claims in published maps and institutional affiliations.

Copyright: (C) 2022 by the authors. Licensee MDPI, Basel, Switzerland. This article is an open access article distributed under the terms and conditions of the Creative Commons Attribution (CC BY) license (https:// creativecommons.org/licenses/by/ $4.0 /)$.
1 Tecnológico Nacional de México/Instituto Tecnológico de Ciudad Guzmán, Ciudad Guzman 49100, Mexico; sergio.sp@cdguzman.tecnm.mx (S.S.P.); m20291054@cdguzman.tecnm.mx (M.A.V.B.); jesus.ms@cdguzman.tecnm.mx (J.E.M.S.)

2 Faculty of Electromechanical Engineering, University of Colima, Colima 28860, Mexico; rjimenez@ucol.mx (R.O.J.B.); ferharo@ucol.mx (F.R.H.)

3 Flextronix Guadalajara Campus Norte, Carretera Base Aérea 5850-23, La Mora, Zapopan 45136, Mexico; Luis.rosas@flex.com (J.L.R.O.); gustavoisrael.riberthgarcia@flex.com (G.I.R.G.)

* Correspondence: jgonzalez71@ucol.mx

\begin{abstract}
This study aims to develop and evaluate an Augmented Reality (AR) application to teach power electronics to beginners. For this purpose, two topics were presented: The first was the design of a series-connected Resistance-Inductor-Capacitor (RLC) circuit in AR, the space-state equations of which were analyzed in an interactive way, and its assembly in a virtual protoboard to analyze the voltage and currents as measured by an oscilloscope. The second presented topic in AR was about Bidirectional Direct Current (DC)-DC converters, known as Buck-Boost; the aim was to study their behavior when energy is exchanged between two systems, usually photovoltaic panels, electric vehicles, and storage systems. The attitudes of the students towards the AR application was significantly better than those towards traditional teaching. The measurements of the developed skills indicated better cognitive performance when using AR technology. The designed AR tool was used in an industry course to explore the students' opinions, who provided valuable feedback.
\end{abstract}

Keywords: augmented reality; electronic circuit simulation; engineering education; mobile learning; UNITY; Vuforia

\section{Introduction}

Training-teaching, in particular at universities, must address various challenges, mainly in engineering, due to expensive or insufficient laboratory equipment or the difficulty in simulating certain experimental conditions.

The challenge in training and teaching lies in promoting professional competencies and the progressive improvement of these competencies by using technological and educational resources such as Information and Communication Technologies (ICTs). These digital learning materials must be effective and of high quality for training and laboratory practice through a different perspective of representing content, phenomena, and simple or complex situations to be addressed in a setting that facilitates learning in engineering areas.

The situation caused by the COVID-19 pandemic has resulted in changes and challenges for university training and restrictions to activities, thus testing the ability of universities to adapt to these changes, and has strongly revived the approach to competency-based learning in a new context. Hence, ICTs play an important role in the development of skills and knowledge acquisition, facilitating the exchange of information and increasing access to diverse content.

Before the pandemic, some ICTs had already been used to help improve learning. Some implemented strategies with the use of the Internet of Things (IoT) [1-3]. Mylonas 
in [1] reported a kit-lab-based on the IoT to motivate energy saving activities through the integration of gamification components and electronic sensors, while Marquez [2] and Jimenez [3] explored the IoT's utility in the academic context. Mancilla [4] developed an IoT device called the Mechatronics and Internet of Things (MEIoT) weather station, combining the necessary skills in educational mechatronics for Industry 4.0. Simiscuka [5] introduced a Virtual Reality (VR) environment combined with IoT devices that allowed users to operate objects in a virtual environment and real IoT objects to perform some laboratory activities.

VR environments have been utilized for training-teaching and also have proven their effectiveness in learning approaches. A VR simulator for fire training with the acquisition of concepts and procedural training was proposed in [6]. The technical characteristics and installation details of photovoltaic system were projected in a virtual world by [7]. The training of lineworkers in energy distribution systems was presented in [8], while the evaluation of a real industrial environment with the inclusion of VR was analyzed in [9]. Radianti presented a review of existing research dedicated to the application of immersive VR in higher education in many disciplines, where engineering was the most popular one identified with $24 \%$ [10]. A similar situation was presented by [11,12]. However, content creation tends to be expensive due to the costs of the head and specialized computer equipment.

\section{Related Work}

Augmented reality technology has been increasingly used in education. The learning effects may be more interesting if a virtual object is merged into a real scenario with AR and the learners' interactive behavior is the same as the real experimental condition, as in the real-time interactivity in the framework of the Teaching Factory between industrial equipment and AR, as suggested in [13]. Wei [14] investigated the impacts of AR on teaching in technical creative design courses in high schools to improve motivation, creativity, and teaching efficiency; this also applies to sports [15], mathematics [16,17], engineering [18,19], and industry [20], along with customers becoming part of the process of robotic cell manufacturing to customize it to their needs [21] or guiding the operators in industry $[22,23]$.

AR technologies have been used in the field of electronics to help understand concepts and their applications in laboratories to increase skills and the understanding of some topics. A series-parallel-mixed resistor electrical circuit simulator with AR components was presented by [24-27] to teach electrical network concepts to engineering students between 20 and 21 years old. Similarly, [28] developed an AR application to teach fifth-grade students about electrical currents in bulbs.

A mobile application, AR-Electronic-Lab, was presented to provide experience with electronic circuits in real life, creating some lab activities with the use of an oscilloscope, diode clipper circuit, and inverting operational amplifier circuit [29]. The training in AR to operate an oscilloscope and function generator was presented by [30], then this training was converted to VR [31].

The fundamental concepts of digital electronic devices such as Boolean algebra and logic gates can be addressed using AR, which was proposed by [32] to help in the identification of seven basic logic gates: AND gate, OR gate, NOT gate, NAND gate, NOR gate, XOR gate, and XNOR gate. Ref. [33] described the design and implementation of AR with the IoT to control and monitor mechatronic systems.

Considering the need for the development of experimental infrastructure and taking into account the related work, there is a wide area for improvement in electronics training-teaching. For this reason, the following AR-electronics-based learning tool is proposed for beginners. We discuss the design and implementation of AR-RLC circuits and a bidirectional DC-DC converter, known as Buck-Boost; the proposed tool was utilized in power electronic courses for college students and in a training course in the industry. 


\section{Methodology Process for Developing the AR-Electronics App}

Teaching generally includes classroom and laboratory classes. These sessions include lectures and activities where the student performs application exercises and completes the laboratory activities. The materials provided in the electronics laboratory activities are manuals, including theoretical and practical developments and application examples. The laboratory manager provides the necessary material to carry them out; however, the material is not always enough for all students, so support tools such as the one presented in this article are always of great help. In the case of power electronics, the student must have prior knowledge of electrical circuits and of the analysis, simulation, and implementation of analog circuits. Furthermore, they must know linear algebra, derivation, and numerical integration.

Bloom's taxonomy has been widely accepted in the educational community indicating the depth of understanding from the knowledge, applications, analysis, synthesis, and evaluation process [34]. To acquire the depth of understanding, educators are motivated to use different teaching techniques; hands-on experiences significantly promote learning at all levels of science education when appropriately designed and guided by qualified educators [35]. Practical laboratory experiences are fundamental to the learning process in all areas of study. Research has shown that students who face well-planned strategies in laboratory experiences obtain problem-solving and critical thinking skills. AR tools are quite efficient to help students understand and motivate them in the training process in the laboratory [36].

The implemented power electronics course for engineering students is summarized in Figure 1. The main topics are RLC circuits, semiconductors, rectifiers, DC-DC converters, and inverters. Two main topics were selected to implement the AR tool: one was approached at the beginning of the course, to motivate the students with the new tool, the other AR topic was approached at the end of the course. Therefore, we can have an overview to see the feasibility of designing a complete course with this tool.

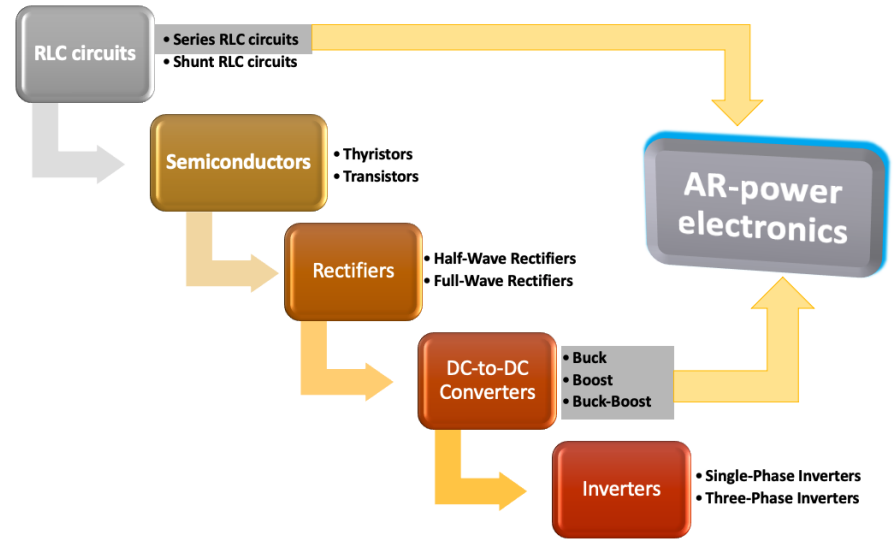

Figure 1. Power electronic course.

The AR-app design methodology is included in Figure 2. For its design, the use of Blender [37] was required for the elaboration of the 3D elements of electronic devices and the export of these designs to UNITY [38] to elaborate and coordinate the activities in the C\# script, together with the time-lapse programming, to build the APK, so that the users can provide the necessary inputs to guide them in the laboratory practices. Even though Vuforia and ARkit have great capabilities for AR applications, ARCore was chosen because it maintains larger maps in terms of monitoring the real-life environment compared to other augmented reality SDKs, such as Vuforia, without neglecting the documentation and existing support, both from Google and the community itself. In addition to the above, ARCore is totally free, and the configuration and integration of ARCore in UNITY is much easier, so that ARCore was used to perform the image tracking and recognition between the real world and augmented reality. 


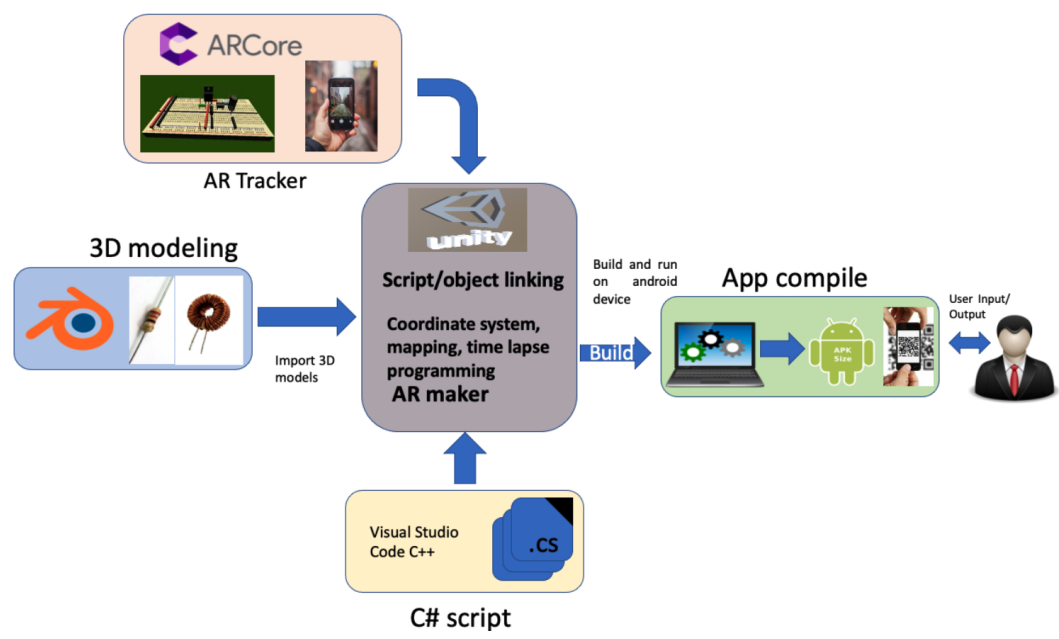

Figure 2. Designing the AR-electronics app in UNITY.

\subsection{Description of the Designed and Developed Electronics App}

An incremental model was adopted for the project design, in which a requirements analysis was performed for the the design of the models and interfaces; their coding and testing were carried out until the proposed changes were achieved and the functionalities added. For the logical architecture of the application, the functional requirements were considered such as the application for mobile devices, $\mathrm{QR}$ code recognition, and interactivity with the user, as well as non-functional requirements such as the usability and acceptable response times. The development tools and libraries used were ARCore [39] and UNITY. Using different APIs, ARCore allows a cellphone to detect its environment, understand the world, and interact with information programmed in UNITY to create interactive 3D dimensional simulations. ARCore uses three key capabilities to integrate virtual content with the real world as viewed through the phone's camera, tracking movement, understanding the environment, and light estimation, allowing the detection of the size and location of objects and the lighting conditions of the environment [39].

To achieve the functionality 3D models developed in Blender, the creation of a 3D scene required at least three key components: models, materials, and lights, along with the editing of objects such as meshes, curves, and surfaces. Once the object has been developed in 3D, it can be exported in FBX format to be used in UNITY 3D. Once exported to UNITY, the developed objects must be assembled using the inspector tab to provide object textures, positions, sizes, and assembly.

Figure 3 illustrates the design to carry out the interaction between the app and the user. Animations with timelines were created using the UNITY 3D (Timeline) sequencer to activate objects, buttons, sliders, and text in such a way that the users control the monitoring of their assembly process, both in the app and with the real elements in the Laboratory.

The electronic components were made from "primitive" shapes included in the UNITY 3D engine. In Figure 4, a parent object called "ARResistor" can be seen, which is an empty GameObject where the elements that make up the resistance are placed as child objects; for example, the GameObject that is selected in the hierarchy in the image is identified by the name "ResistorBody", e.g., the body of the resistor. The inspector shown in Figure 4 illustrates that the GameObject has a "Transform" component, which provides information about the position, rotation, and scale of the GameObject, this component having its three parameters manipulated to give the shape and proportion and achieve the appearance that provides the GameObject the resistor's shape. The "Mesh Filter" and "ResistorBody" components were placed to provide the typical characteristics of resistors. Similarly, the inductor, connection cables, and capacitors were created in this way. 


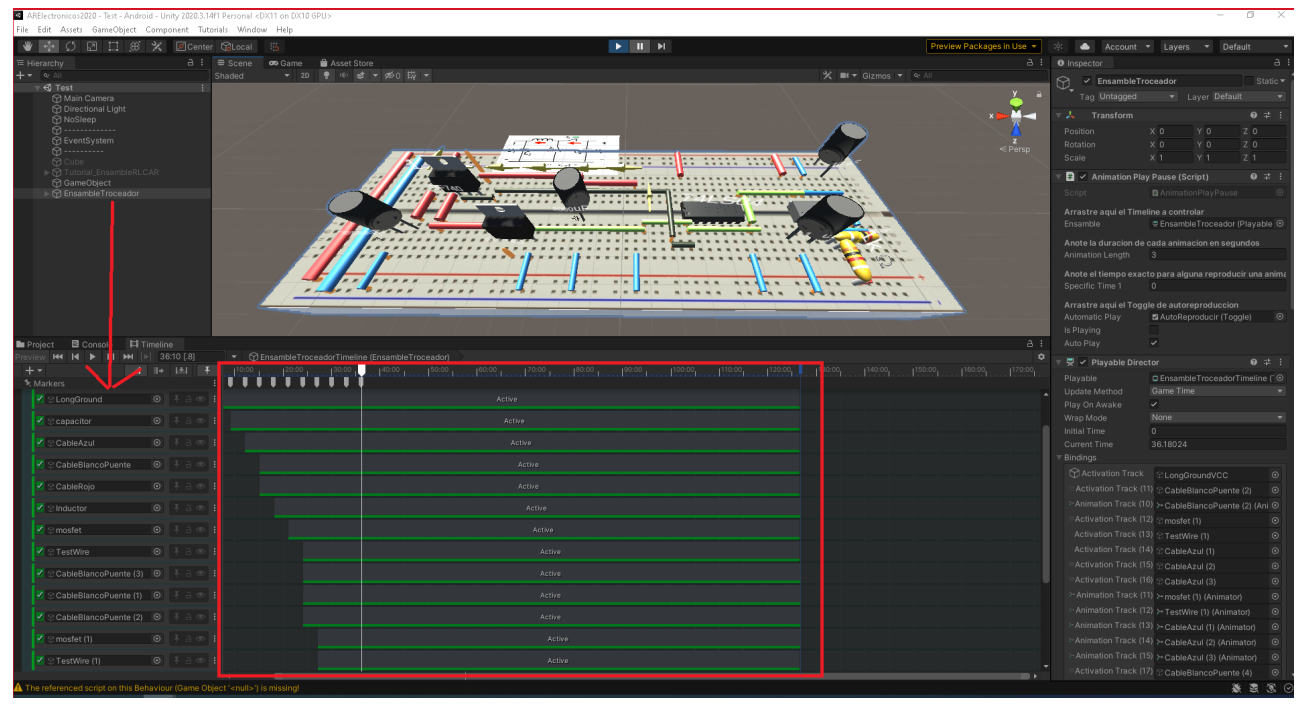

Figure 3. Timeline animations.

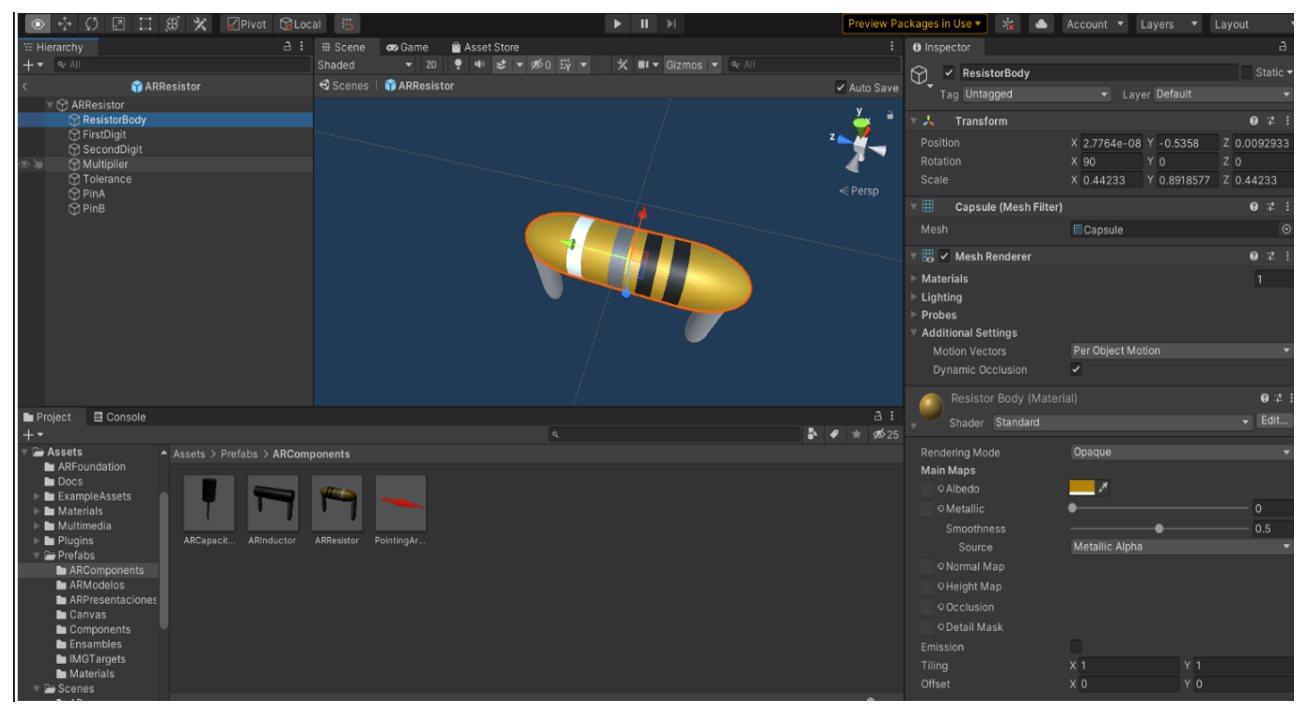

Figure 4. AR—resistor GameObject.

To control the scenes, some scripts were designed. For instance, "AssembleTroceador" in this case is the "Parent" object of a group of 3D models under its hierarchy. It contains the "AnimationPlayPause" script that is responsible for pausing, rewinding, and resuming the playback of the main timeline of the animation in each scene. Immediately under the hierarchy, known as the child object, a script named "UIHandler" is programmed (Figure 5) in which the buttons "Previous" and "Next" of the canvas with the name "AnimationControl" are added. This script is in charge of activating and disabling onscreen images, as well as interactive on-screen menu-triggered events.

Once we have the elements to interact with, it is necessary to make adjustments to the User Interface (UI) using the UNITY GameObject menu and the Rect Tool to move, resize, and rotate the UI elements according to the interaction and give functionality to the programmed elements in UNITY. Then, an APK is built for the topic of RLC circuits configured to carry out the assembly in the laboratory and the mathematical analysis of the circuit. Similarly, for the bidirectional Buck-Boost converter, another APK is built to individually analyze the Buck and Boost converters and for it to work as a bidirectional converter. 


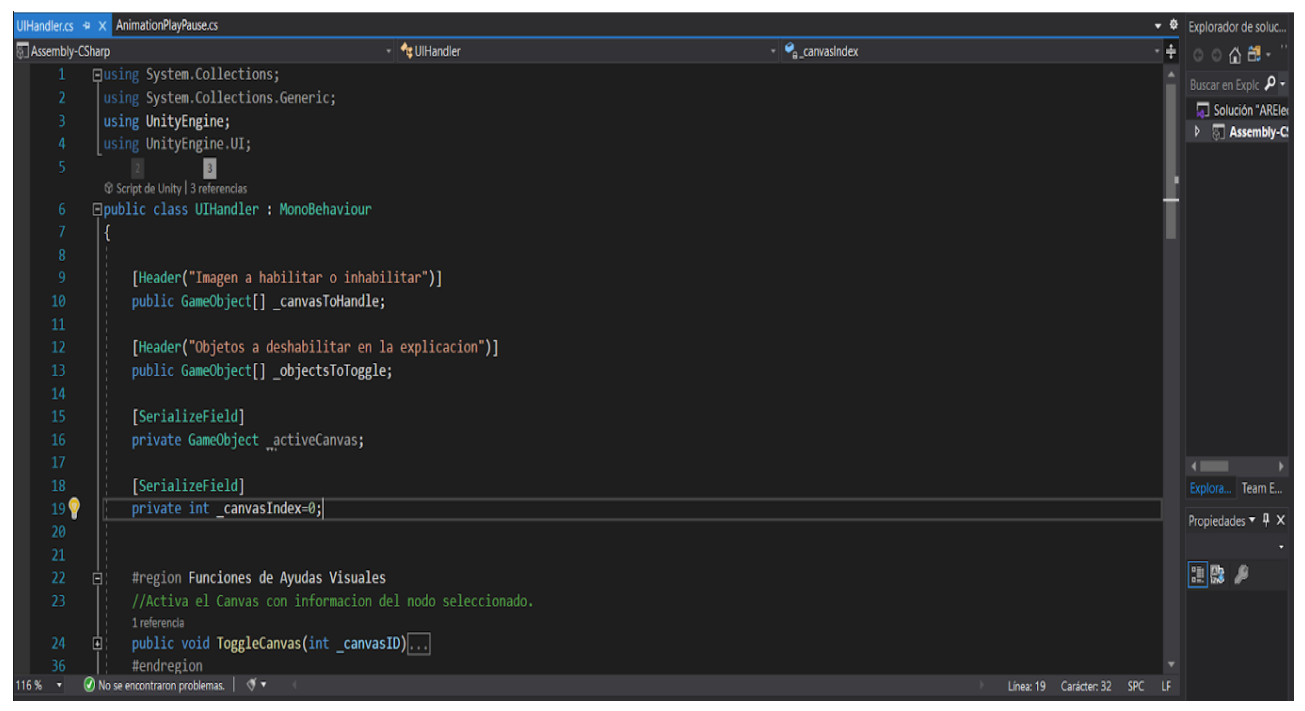

Figure 5. Script UIHandler to activate/deactivate visual aid or scene changes.

\subsection{Development of the AR for RLC Circuits}

One of the main problems when teaching the mathematical analysis of RLC circuits is that some students cannot obtain their state-space equations. Hence, these equations were obtained interactively by designing them in AR, guiding the user to understand their modeling. The RLC circuit implemented in this study considers a series connection, as shown in Figure 6a, and the equations in state-space are given by Equation (1) [40].

$$
\left[\begin{array}{l}
\frac{d V_{C}(t)}{d t} \\
\frac{d I_{L}(t)}{d t}
\end{array}\right]=\left[\begin{array}{cc}
0 & \frac{1}{C} \\
-\frac{1}{L} & -\frac{R}{L}
\end{array}\right]\left[\begin{array}{l}
V_{C}(t) \\
I_{L}(t)
\end{array}\right]+\left[\begin{array}{c}
0 \\
\frac{1}{L}
\end{array}\right]\left[\begin{array}{c}
0 \\
v(t)
\end{array}\right]
$$

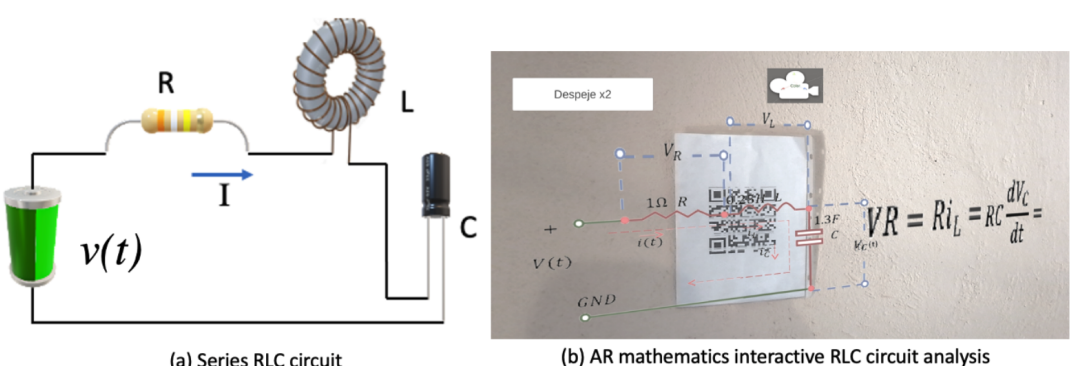

(a) Series RLC circuit

(b) AR mathematics interactive RLC circuit analysis

Figure 6. RLC circuit: AR GUI interactive RLC circuit mathematics analysis.

The design of the AR for RLC circuits was divided into two stages: an interactive mathematical explanation for obtaining its mathematical model in state spaces and representing the RLC circuit in two differential equations (Figure 6b); the assembly of the RLC circuit in an electronic protoboard, showing the devices mounted on the protoboard step by step. Additionally, the behavior of the signals for voltage and current was added, as visualized in an oscilloscope (Figure 7), which shows the student how to place the tips of the oscilloscope within the RLC circuit to obtain the responses of the waveforms. Figure 7 illustrates the circulation of energy through each of the devices with arrows as well as it magnitude values. 


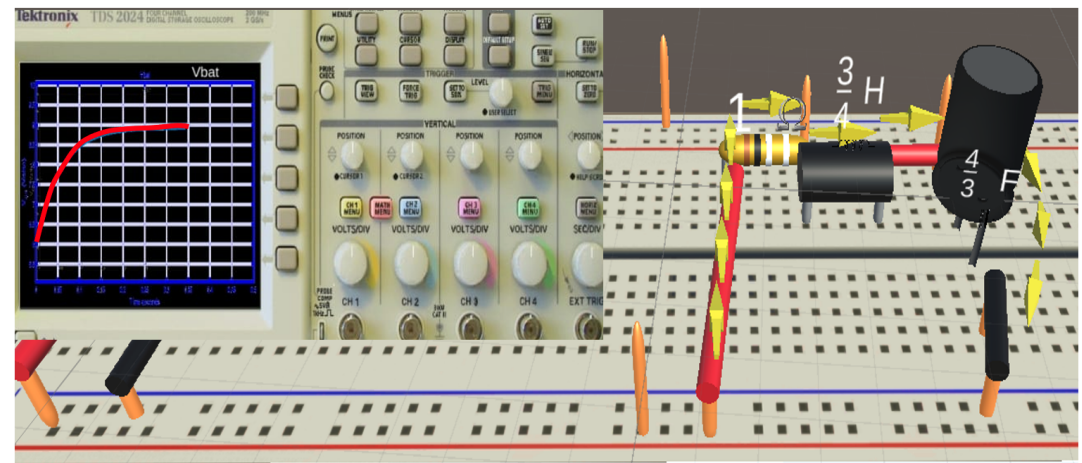

Figure 7. AR-RLC circuit GUI to assemble devices on an electronic breadboard.

\subsection{Development of AR for the DC-DC Buck-Boost Converter}

Figure 8a shows the electrical diagram of the bidirectional Buck-Boost converter. This converter has an inductor, a capacitor, two power switches, and two voltage sources; this guarantees a bidirectional power flow, which makes it suitable in applications in electric vehicles and renewable energy. Thus, this results in the students showing a particular interest in this type of converter. The bidirectional Buck-Boost converter has two voltage sources at the ends, V1 and V2; the switches S1 and S2 work in a complementary way; therefore, it has four modes of operation according to the voltage level of the sources and the state of the switches (Figure 8b) [41].

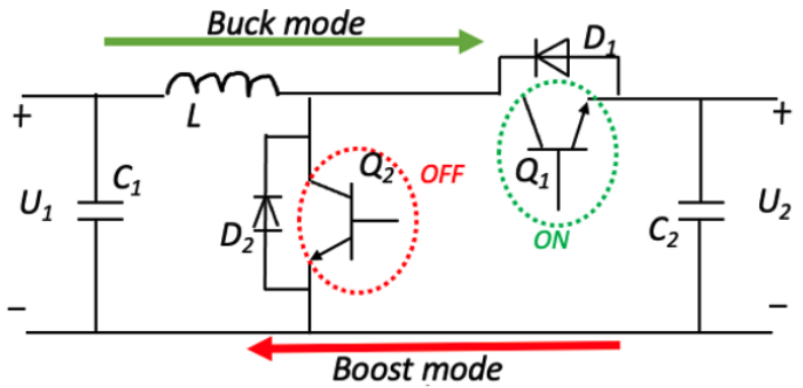

(a)
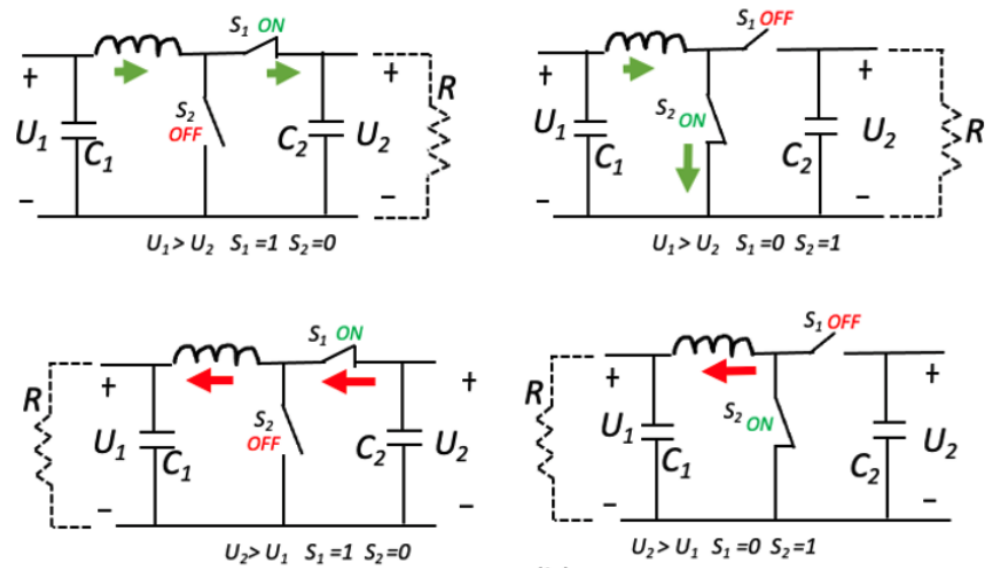

(b)

Figure 8. BidirectionalDC-DC converter topology.

The bidirectional converter design in AR is divided into two stages, one for the Buck converter (Figure 9a) and one for the Boost converter (Figure 9b). The flow of energy that circulates from one battery to the other is shown with animations to clarify its operation. Furthermore, the waveforms of the voltage across Capacitors 1 and 2 are shown in Figure 9c. 


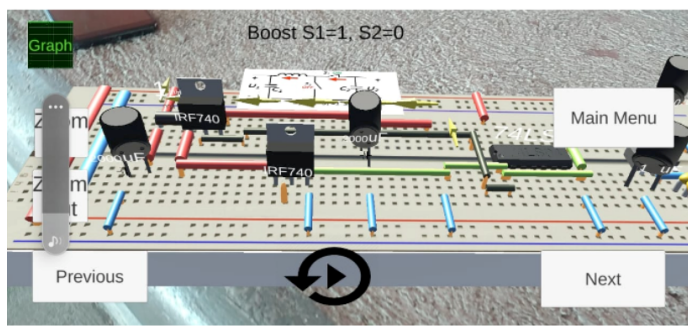

(a)

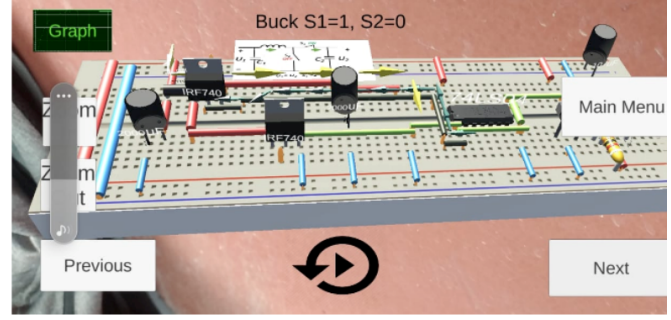

(b)

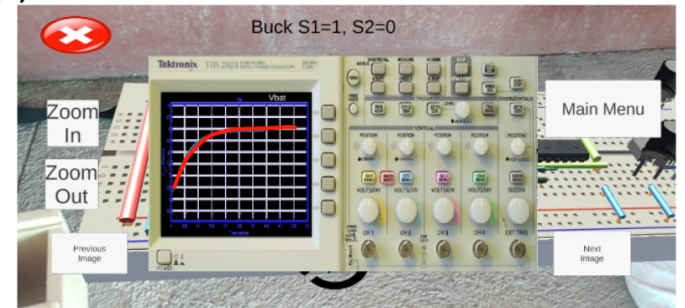

(c)

Figure 9. AR GUI to assemble the Buck/Boost converter. (a) Connecting guide for Buck; (b) Assembly help for Boost; (c) Using an oscilloscope to measure the voltage of the batteries.

\section{Experimental Procedure}

\subsection{Participants}

Table 1 depicts the participants that used the created tool. Although this tool was designed for engineering students, it was also used by students of the Automotive Teaching Center CD GUZMAN to encourage early interest and vocation in engineering topics. For all fifteen participants (15-19 years old), this was the first time they had carried out engineering activities, and they did not have any knowledge about electronics, so the assembly of the RLC circuit was implemented physically and with the support of the app.

Table 1. Participants using the AR-electronics app.

\begin{tabular}{cccc}
\hline Activity & $\begin{array}{c}\text { Vocational } \\
\text { Students }\end{array}$ & $\begin{array}{c}\text { University } \\
\text { Students }\end{array}$ & $\begin{array}{c}\text { Industry } \\
\text { Workers }\end{array}$ \\
\hline RLC physical experimentation & $\mathrm{X}$ & $\mathrm{X}$ & $\mathrm{X}$ \\
Mathematical RLC analysis & & $\mathrm{X}$ & $\mathrm{X}$ \\
Buck-Boost physical experimentation & & $\mathrm{X}$ & $\mathrm{X}$ \\
\hline
\end{tabular}

There were 17 university students in their second year between 20 and 25 years old from the Technological Institute of Ciudad Guzmán who participated, for whom their first exposure to electronics was electrical circuits and basic electronics, as well as math courses. Therefore, these participants used the AR app to support the assembly of the RLC circuit, the analysis of the equations in state space, and the bidirectional Buck-Boost converter assembly during the implemented courses. Figure 10 shows some students using the ARelectronics app, from which a series of benefits could be established, as illustrated in Table 2, where the characteristics, services, and benefits of the developed app are mentioned.

One of the main activities of a researcher is to keep in touch with the industry and to be able to carry out joint research or offer services, including training courses for their staff. Therefore, a power electronics course was implemented with the help of AR, which was taught to 6 workers between 30 and 50 years old at a company [42]. Their specialty was in related areas such as plant engineers, technicians, supervisors, and training. It is worth mentioning that [42] is a company dedicated to electronic design with applications in the automotive, industrial, medical, and technological industries with collaboration in more than 30 countries; therefore, the AR tool used in the power electronics courses could have an international impact. 


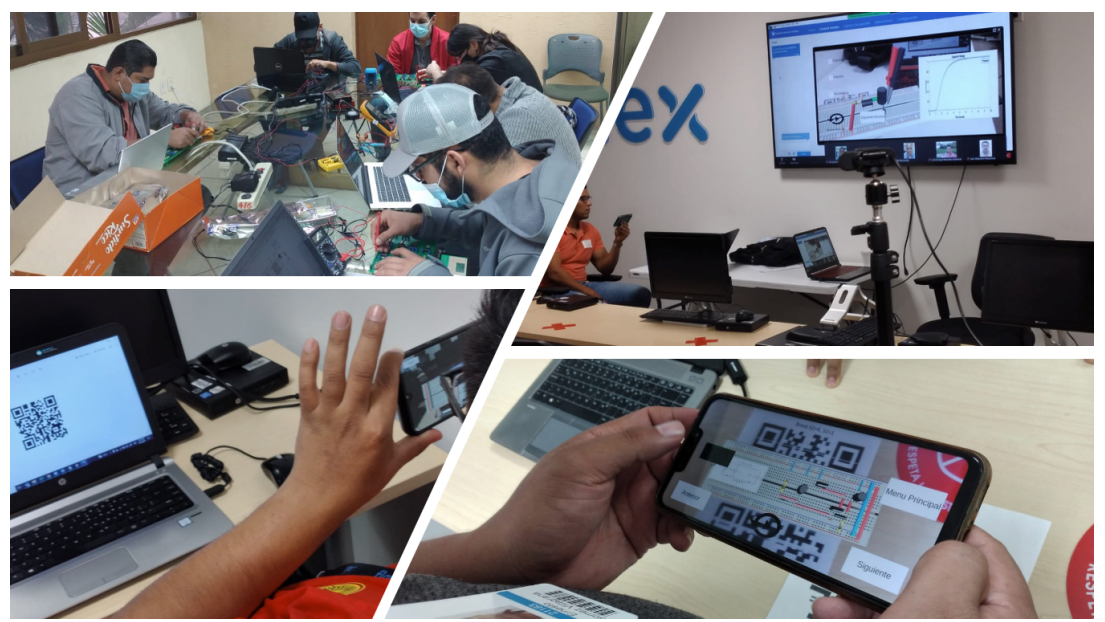

Figure 10. Using the AR-electronics app.

Table 2. List of features and services on offer of the AR-electronics app.

\begin{tabular}{cc}
\hline $\mathbf{N}$ & Findings of AR-Electronics App Use \\
\hline 1 & Students show motivation in the class \\
2 & Students with active participation and self-paced learning \\
3 & Reduce time to accomplish activities in the laboratory \\
4 & Development of independence to accomplish tasks \\
5 & Better understanding for teamwork and collaborative learning \\
6 & The app provides assistance with on-site operation during activities in the laboratory \\
7 & Support the mathematics analysis of RLC circuits \\
8 & Students learn faster and more easily \\
\hline
\end{tabular}

\subsection{Perceptions and Experiences of the Technologies}

The aim of this study was to examine the effect of the AR tool in terms of students' knowledge improvement and cognitive load. The general evaluation of the application of AR in electronics courses is presented in Table 3 to examine the trainers' perception of the general aspects, seven questions focused on the AR app's use, since its installation, and of the interactive part. They were encouraged to answer if they totally agree, agree, disagree, or totally disagree. Figure 11 illustrates that the majority of the students totally agreed that AR can help them have a better understanding of the topics; only three of the respondents disagreed, especially on the part regarding industry application, and in their comments, they mentioned that this tool could distract them from their work activities.

Table 3. General evaluation for the use of the AR-electronics app.

\begin{tabular}{cc}
\hline N & Question for General Evaluation \\
Q1 & Was the installation of the app easy? \\
Q2 & Was the app useful and interactive? \\
Q3 & Did the AR app help me keep my attention during the course? \\
Q4 & Did I enjoy studying this course? \\
Q5 & Do you think that augmented reality helped you in your training? \\
Q6 & Is augmented reality more efficient to learn than a web page? \\
Q7 & Am I willing to recommend this AR/3D learning tool to my friends? \\
\hline
\end{tabular}




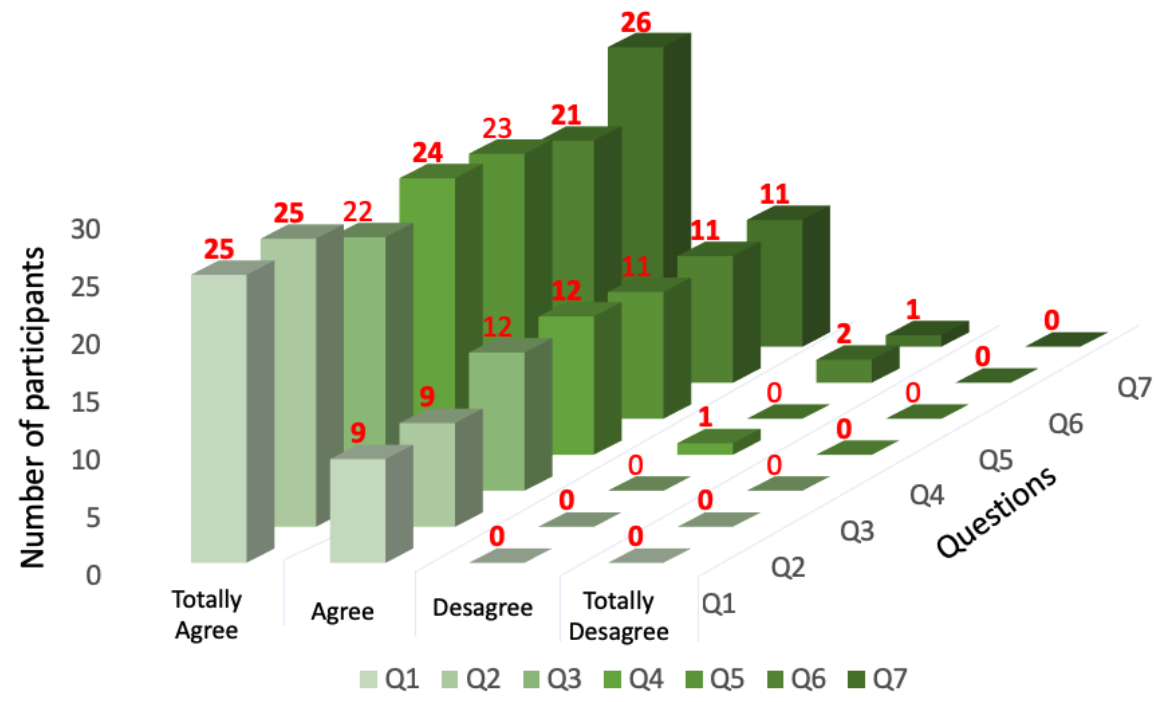

Figure 11. AR-electronics app's general evaluation.

Table 4 shows four questions about the use of AR-RLC circuits; the questions were focused on the mathematical interactivity part to understand the state space equations and the assembly circuit part, as well as the measurements made on the resistance, inductance, and capacitance to measure the voltage and current, as they would with an oscilloscope. In this survey, they were asked to rate the AR app from $1-5$, where the highest rating was 5 . Figure 12 shows the survey results, where the acceptance can be observed mainly in the comments part. The perception of both the mathematical part and the assembly of the elements was good. Some with electronics knowledge stated that the AR app can be a bit tedious, suggesting a faster interaction in the assembly on the protoboard. However, this could be counterproductive for beginners.

Table 4. Survey on the use of the AR-RLC circuits.

\begin{tabular}{cc}
\hline $\mathbf{N}$ & Questions about the AR-RLC Circuits' Use \\
\hline Q1 & Is the mathematical analysis of the RLC circuit in AR clear and did it help me understand it? \\
Q2 & Is a math presentation in AR better than a power point presentation? \\
Q3 & Did the use of the AR-3D RLC app help me better understand the realistic assembly of RLC \\
Q4 & circuits? \\
\hline
\end{tabular}

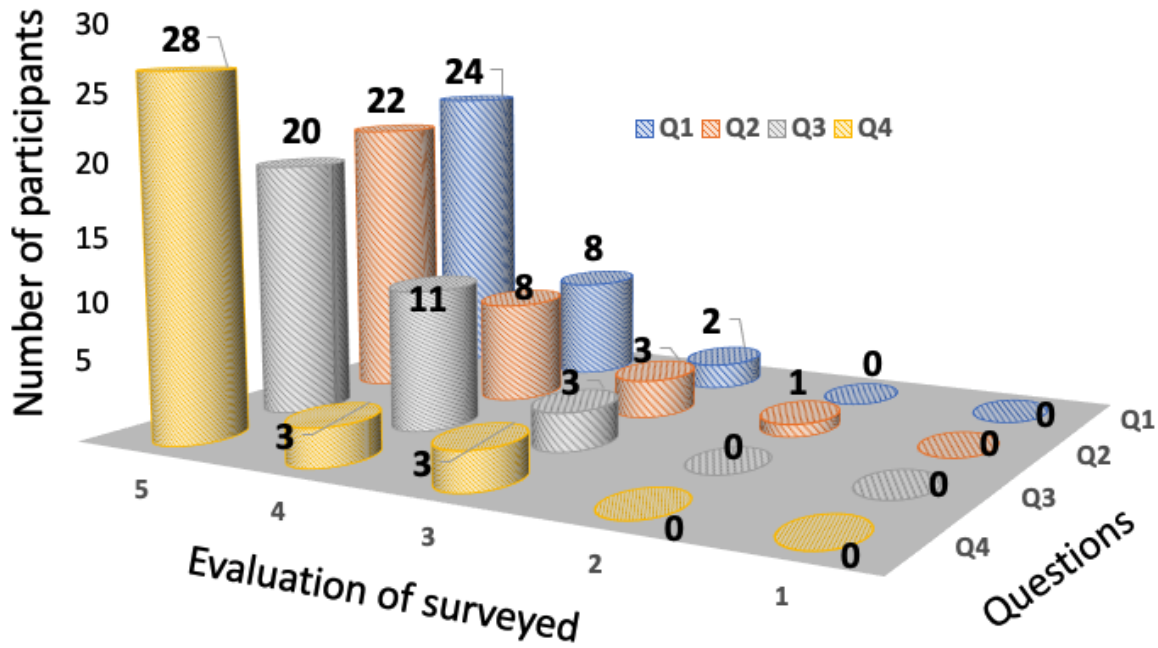

Figure 12. AR-RLC circuits' survey. 
In the case of bidirectional DC-DC converters, Table 5 shows four questions regarding the improvement in understanding by using the AR app. They indicated less confusion about the behavior of the Buck or Boost converter, as well as a better appreciation when the AR assembly is shown on an electronic breadboard. Similarly, they were asked to rate the AR app from 1-5, where the highest rating was 5 (Figure 13).

Table 5. Survey for the use of the AR DC-DC converters.

\begin{tabular}{cc}
\hline $\mathbf{N}$ & Questions about the DC-DC Converters \\
\hline Q1 & Do I better understand how power flows in a bidirectional Buck-Boost converter? \\
Q2 & Do I better understand the interaction between the switches? \\
Q3 & With AR animations, do I understand when they work as Buck or Boost? \\
Q4 & Does the AR-3D assembly of the Buck-Boost circuit on the protoboard help me do it \\
& easier physically? \\
\hline
\end{tabular}

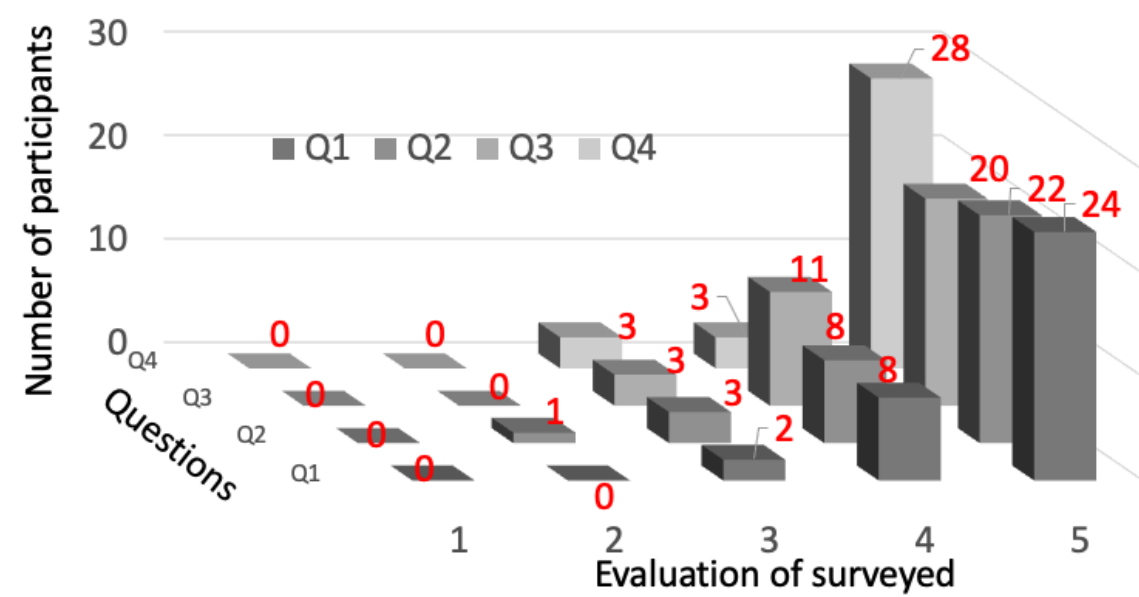

Figure 13. AR-DC-DC survey.

\section{Results and Discussion}

During the course, the university students were divided into two subgroups of 13 students: the first group was called the Control-Group (CG) following the traditional teaching, while the Experimental-Group (EG-AR) used the AR app in the subjects of RLC circuits and DC-DC converters. In these two subjects, a pre-test was applied, and its average evaluation is shown in Figure 14 and Table 6. At the end of the course, a laboratory activity was implemented to reinforce their knowledge and evaluate the use of the AR app. The results of the post-test evaluation are illustrated in Figure 14. Table 6 illustrates the statistical analysis of the ANOMA method applied during the pre-test and the final test to establish noteworthy differences among the obtained knowledge of both groups. The ANOMA method indicated that there was no significant difference during the pre-test $(p=0.532>0.05)$, indicating that very similar knowledge had been acquired between the CG and EG-AR groups. In the post-test, ANOMA provided a value $(p=0.006<0.05)$, indicating a difference in the learning achieved.

Table 6. Participating students.

\begin{tabular}{ccccccc}
\hline & Pre-Test & \multicolumn{3}{c}{ Post-Test } \\
\hline & Average & F & $\boldsymbol{p}$ & Average & F & $p$ \\
\hline TT group & 6.77 & 5.1263 & 0.033 & 7.35 & 8.839 & 0.0066 \\
AR-Electronics app group & 6.9 & & & 8.7 & & \\
\hline
\end{tabular}




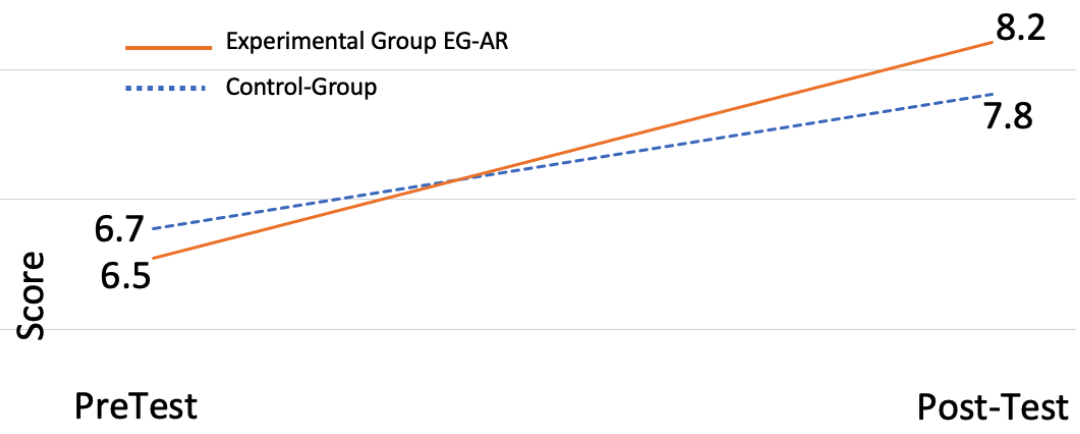

Figure 14. Knowledge improvement measurement.

Table 7 depicts the evaluation rubric used to evaluate students on the subject of RLC circuits, giving greater importance to physical assembly in the laboratory and to mathematical analysis. Table 8 describes the evaluation rubric utilized to assess students knowledge on the topic of DC-DC converters, and greater importance was given to physical assembly for Buck, Boost, Buck-Boost, and the PWMcontrol.

Table 7. Evaluation rubric for RLC analysis.

\begin{tabular}{ccc}
\hline $\mathbf{N}$ & Instructions for Learning & Evaluation Parameter \\
\hline 1 & Identify the differences of a resistor, coil, and capacitor & $5 \%$ \\
2 & Explain the behavior of a series-connected RLC circuit & $10 \%$ \\
3 & Use the protoboard properly & $10 \%$ \\
4 & Physical assembly of the RLC circuit in the laboratory & $35 \%$ \\
5 & Mathematical analysis & $20 \%$ \\
6 & Measurements & $10 \%$ \\
7 & Conclusions demonstrating knowledge of RLC circuits & $10 \%$ \\
\hline
\end{tabular}

Table 8. Evaluation rubric for Buck-Boost analysis.

\begin{tabular}{ccc}
\hline $\mathbf{N}$ & Instructions for Learning & Evaluation Parameter \\
\hline 1 & Explain the behavior of Buck mode & $5 \%$ \\
2 & Explain the behavior of Boost mode & $5 \%$ \\
3 & Physical assembly of the Buck circuit in the laboratory & $25 \%$ \\
4 & Physical assembly of the Boost circuit in the laboratory & $25 \%$ \\
5 & Physical assembly of the PWM controller & $20 \%$ \\
6 & Measurements & $10 \%$ \\
7 & Conclusions about the bidirectional Buck-Boost converter & $10 \%$ \\
\hline
\end{tabular}

The results presented allowed us to realize that the student's motivation improved with the developed tool; they expressed interest in continuing to learn using this type of modern tool, suggesting the feasibility of extending the tool to all the topics of a power electronics course. The increase in the capacities shown by the students who used the tool makes it possible to foresee that the professionals who graduate will be highly qualified, as required by the country and society. Therefore, this gives, to the authors, the incentive to continue improving and expanding the tool.

\section{Conclusions}

In this study, AR technology to teach power electronics was used. An augmented reality environment for RLC circuits and Buck-Boost converters to explore the impacts of using this technology was developed. The experimental results indicated a positive effect on the students compared to the traditional teaching approach; therefore, the possibility of designing the entire course with AR tools in the future is appropriate. The study aimed to measure the skills obtained and the motivation of the users. Hence, the results indicated 
better cognitive performance with $40 \%$ more retention for the activities carried out, so it is feasible to continue designing tools for the entire electronics course. Furthermore, the exploration carried out with the AR tool to train industry workers indicated its acceptance. Encouraging comments for troubleshooting these tools were given.

Author Contributions: J.M.G.L. and R.O.J.B. planned the strategy and the investigation; J.E.M.S. gave the statistical analysis and reviewed the writing; J.L.R.O. and G.I.R.G. contributed with materials and the implementation of the app in the industry course; J.M.G.L. and F.R.H. wrote and edited the paper; S.S.P. and M.A.V.B. implemented the programming. All authors have read and agreed to the published version of the manuscript

Funding: This research received no external funding

Institutional Review Board Statement: Not applicable.

Informed Consent Statement: Informed consent was obtained from all subjects involved in the study.

Data Availability Statement: Not applicable.

Acknowledgments: The authors are deeply grateful to Consejo Nacional de Ciencia y Tecnología (CONACYT).

Conflicts of Interest: The authors declare no conflict of interest.

\section{References}

1. Mylonas, G.; Amaxilatis, D.; Pocero, L.; Markelis, I.; Hofstaetter, J.; Koulouris, P. An educational IoT lab kit and tools for energy awareness in European schools. Int. J. Child-Comput. Interact. 2019, 20, 43-53. [CrossRef]

2. Marquez, J.; Villanueva, J.; Solarte, Z.; Garcia, A. IoT in education: Integration of objects with virtual academic communities. New Adv. Inf. Syst. Technol. 2016, 444, 201-212. [CrossRef]

3. Jimenez Betancourt, R.O.; Gonzalez Lopez, J.M.; Barocio Espejo, E.; Concha Sanchez, A.; Villalvazo Laureano, E.; Sandoval Perez, S.; Contreras Aguilar, L. Iot-based electricity bill for domestic applications. Sensors 2020, 20, 6178. [CrossRef] [PubMed]

4. Carlos-Mancilla, M.A.; Luque-Vega, L.F.; Guerrero-Osuna, H.A.; Ornelas-Vargas, G.; Aguilar-Molina, Y.; González-Jiménez, L.E. Educational Mechatronics and Internet of Things: A Case Study on Dynamic Systems Using MEIoT Weather Station. Sensors 2021, 21, 181. [CrossRef] [PubMed]

5. Simuscuka, A.A.; Markande, T.M.; Muntean, G.M. Real-virtual world device synchronization in a cloud-enabled social virtual reality IoT network. IEEE Access 2019, 7, 106588-106599. [CrossRef]

6. Morelot, S.; Garrigou, A.; Dedieu, J.; NKaoua, B. Virtual reality for fire safety training: Influence of immersion and sense of presence on conceptual and procedural acquisition. Comput. Educ. 2021, 166, 104145. [CrossRef]

7. Gonzalez Lopez, J.M.; Jimenez Betancourt, R.O.; Ramirez Arredondo, J.M.; Villalvazo Laureano, E.; Rodriguez Haro, F. Incorporating virtual reality into the teaching and training of Grid-Tie photovoltaic power plants design. Appl. Sci. 2019, 9, 4480. [CrossRef]

8. Santamaria-Bonfil, G.; Ibanez, M.B.; Perez-Ramirez, M.; Arroyo-Figueroa, G.; Martinez-Alvarez, F. Learning analytics for student modeling in virtual reality training systems: Lineworkers case. Comput. Educ. 2020, 151, 103871. [CrossRef]

9. Wolfartsbergeri, J. Analyzing the potential of Virtual Reality for engineering design review. Autom. Constr. 2019, 104, 27-37. [CrossRef]

10. Radianti, J.; Majchrzak, T.A.; Fromm, J.; Wohlgenannt, I. A systematic review of immersive virtual reality applications for higher education: Design elements, lessons learned, and research agenda. Comput. Educ. 2020, 147, 103778. [CrossRef]

11. di Lanzo, J.A.; Valentine, A.; Sohel, F.; Yapp, A.Y.; Muparadzi, K.C.; Abdelmalek, M. A review of the uses of virtual reality in engineering education. Comput. Appl. Eng. Educ. 2020, 28, 748-763. [CrossRef]

12. Huang, W.; Roscoe, R.D. Head-mounted display-based virtual reality systems in engineering education: A review of recent research. Comput. Appl. Eng. Educ. 2021, 29, 1420-1435. [CrossRef]

13. Siatras, V.; Athanasopoulou, L.; Alexopoulos, K.; Stavropoulos, P.; Mourtzis, D. Applying the Teaching Factory Paradigm and Augmented Reality Technology for Operator Training in Assembly Operations. 2021. Available online: https://papers.ssrn.com/ sol3 / papers.cfm?abstract_id=3859475 (accessed on 26 December 2021).

14. Wei, X.; Weng, D.; Liu, Y.; Wang, Y. Teaching based on augmented reality for a technical creative design course. Comput. Educ. 2015, 81, 221-234. [CrossRef]

15. Soltani, P.; Morice, A.H. Augmented reality tools for sports education and training. Comput. Educ. 2015, 155, 103923. [CrossRef]

16. Ibanez, M.B.; Portillo, A.U.; Cabada, R.Z.; Barron, M.L. Impact of augmented reality technology on academic achievement and motivation of students from public and private Mexican schools. Comput. Educ. 2015, 145, 103734. [CrossRef]

17. Rossano, V.; Lanzilotti, R.; Cazzolla, A.; Roselli, T. Augmented reality to support geometry learning. IEEE Access 2020, 8, 19679344. [CrossRef] 
18. Li, W.; Nee, A.Y.C.; Ong, S.K. A state-of-the-art review of augmented reality in engineering analysis and simulation. Multimodal Technol. Interact. 2017, 1, 17. [CrossRef]

19. Berkemeier, L.; Zobel, B.; Werning, S.; Ickerott, I.; Thomas, O. Engineering of augmented reality-based information systems. Bus. Inf. Syst. Eng. 2019, 61, 67-89. [CrossRef]

20. Fraga-Lamas, P.; Fernandez-Carames, T.M.; Blanco-Novoa, O.; Vilar-Montesinos, M.A. A review on industrial augmented reality systems for the industry 4.0. IEEE Access 2018, 6, 113358-113375. [CrossRef]

21. Mourtzis, D.; Synodinos, G.; Angelopoulos, J.; Panopoulos, N. An augmented reality application for robotic cell customization Procedia CIRP 2020, 90, 654-659. [CrossRef]

22. Hayden, E.; Wang, K.; Wu, C.; Cao, S. Augmented Reality Procedure Assistance System for Operator Training and Simulation. Proc. Hum. Factors Ergon. Soc. Annu. Meet. 2020, 64, 1175-1180. [CrossRef]

23. Bosch, T.; Van Rhijn, G.; Krause, F.; Könemann, R.; Wilschut, E.S.; de Looze, M. Spatial augmented reality: A tool for operator guidance and training evaluated in five industrial case studies. In Proceedings of the 13th ACM International Conference on PErvasive Technologies Related to Assistive Environments, Corfu, Greece, 30 June-3 July 2020; pp. 1-7.

24. Lucas, P.; Vaca, D.; Dominguez, F.; Ochoa, X. Virtual circuits: An augmented reality circuit simulator for engineering students. In Proceedings of the 2018 IEEE 18th International Conference on Advanced Learning Technologies (ICALT), Mumbai, India, 9-13 July 2018; pp. 380-384. [CrossRef]

25. Selek, M.; Kıymaz, Y.E. Implementation of the augmented reality to electronic practice. Comput. Appl. Eng. Educ. 2020, 28, 420-434. [CrossRef]

26. Avilés, F.R.; Cruz, C.A. Mobile augmented reality on electric circuits. In Proceedings of the IEEE Computing Conference, London, UK, 18-20 July 2017; pp. 660-667.

27. Álvarez-Marín, A.; Velázquez-Iturbide, J.Á.; Castillo-Vergara, M. Technology Acceptance of an Interactive Augmented Reality App on Resistive Circuits for Engineering Students. Electronics 2021, 10, 1286. [CrossRef]

28. Baran, B.; Yecan, E.; Kaptan, B.; Pasayigit, O. Using augmented reality to teach fifth grade students about electrical circuits. Educ. Inf. Technol. 2020, 25, 1371-1385. [CrossRef]

29. Ozuag, M.; Canturk, I.; Ozyilmaz, L. Augmented Reality-Based Simulation of Some Basic Electrical Circuits Which Requires Oscilloscope for Analysis without Hardware. J. Circuits Syst. Comput. 2020, 29, 2050096. [CrossRef]

30. Singh, G.; Mantri, A.; Sharma, O.; Dutta, R.; Kaur, R. Evaluating the impact of the augmented reality learning environment on electronics laboratory skills of engineering students. Comput. Appl. Eng. Educ. 2019, 27, 1361-1375. [CrossRef]

31. Singh, G.; Mantri, A.; Sharma, O.; Kaur, R. Virtual reality learning environment for enhancing electronics engineering laboratory experience. Comput. Appl. Eng. Educ. 2021, 29, 229-243. [CrossRef]

32. Aviles-Cruz, C.; Villegas-Cortez, J. A smartphone-based augmented reality system for university students for learning digital electronics. Comput. Appl. Eng. Educ. 2019, 27, 615-630. [CrossRef]

33. Stark, E.; Kucera, E.; Haffner, O.; Drahos, P.; Leskovsky, R. Using Augmented Reality and Internet of Things for Control and Monitoring of Mechatronic Devices. Electronics 2020, 9, 1272. [CrossRef]

34. Crompton, H.; Burke, D.; Lin, Y.C. Mobile learning and student cognition: A systematic review of PK-12 research using Bloom's Taxonomy. Br. J. Educ. Technol. 2019, 50, 684-701. [CrossRef]

35. Kizilaslan, A.; Zorluoglu, S.L.; Sozbilir, M. Improve learning with hands-on classroom activities: Science instruction for students with visual impairments. Eur. J. Spec. Needs Educ. 2021, 36, 371-392. [CrossRef]

36. Yechkalo, Y.; Tkachuk, V.; Hruntova, T.; Brovko, D.; Tron, V. Augmented Reality in Training Engineering Students: Teaching Methods. Available online: http:/ / ds.knu.edu.ua/jspui/handle/123456789/2555 (accessed on 26 December 2021).

37. Blender. The Blender Foundation. Available online: https://www.blender.org/ (accessed on 26 December 2021).

38. UNITY. UNITYLabs. Available online: https:/ / unity.com (accessed on 26 December 2021).

39. ARCore. Google. Available online: https:/ / developers.google.com/ar (accessed on 26 December 2021).

40. Rashid, M.H. Power Electronics Handbooks, 4th ed.; Elsevier: Amsterdam, The Netherlands, 2017.

41. Venkit, S.M.; Athira, P.C. Solar powered ZCS bidirectional buck-boost converter used in battery energy storage systems. In Proceedings of the 2016 IEEE International Conference on Circuit, Power and Computing Technologies (ICCPCT), Nagercoil, India, 18-19 March 2016; pp. 1-5.

42. Flextronics. Available online: https://flex.com/ (accessed on 28 December 2021). 